\title{
Extranodal B Cell Lymphoma in the Trachea of a Domestic Cat
}

\author{
Mariana de Palha Brito Jardim', Gabriela de Carvalho Cid', Ana Carolina Azevedo Meirelles², \\ Cristiane Brandão Damico ${ }^{3}$, Vivian de Assunção Nogueira ${ }^{4}$ \& Heloísa Justen Moreira de Souza ${ }^{5}$
}

\begin{abstract}
Background: Primary tracheal tumors are considered uncommon in veterinary medicine and among them extranodal tracheal lymphoma, which is a neoplastic type, has rarely been described, especially with the use of immunophenotyping. Consequently, there is a lack of knowledge inherent to the characteristics of this tumor type in felines and as a result little information on how to deal with animals affected by this disease. Therefore, there is a need for more studies focusing on this matter. The objective of this work is to report a case of extranodal B cell lymphoma in the trachea of a domestic cat and point out the clinical and pathological characteristics of this neoplastic type.

Case: A 5-year-old domestic cat, of an oriental breed, was taken to a veterinary clinic exclusively for cats in Rio de Janeiro, Brazil. The main complaint was difficulty in breathing and loss of appetite and historical data included intolerance to exercise. A clinical examination confirmed inspiratory dyspnea and upper respiratory sounds. Hematological and serum biochemical exams did not evidence any noteworthy changes and the cat was considered negative for feline viral leukemia and feline immunodeficiency viruses through serological and molecular testing. However, in the radiographic examination of the thoracic cervical region, an opacity was observed that occluded part of the tracheal lumen and this was suggestive of a mass in the initial third of the trachea, measuring $0.5 \mathrm{~cm}$ in diameter. The animal was stabilized and then $24 \mathrm{~h}$ after admission underwent inspection of the oral cavity and a biopsy of the tracheal mass was performed. Cytology of the specimen was suggestive of lymphoma. The treatment of choice was: lomustine with a single, oral dose of $10 \mathrm{mg}$; vincristine sulfate with a single intravenous dose of $0.75 \mathrm{mg} / \mathrm{m}^{2}$; and methylprednisolone acetate with a single intramuscular dose of $20 \mathrm{mg}$. A second radiograph taken $24 \mathrm{~h}$ after the chemotherapy showed that the tracheal mass had shrunk to 0.3 $\mathrm{cm}$ in diameter. Seven days after the treatment adopted for lymphoma, the mass was no longer visible. Histopathological analysis and immunohistochemistry supported the diagnosis of B cell lymphoma. A 36-month follow-up after the initial admission showed that the cat was in good health, without any respiratory signs and/or alterations in imaging tests that could suggest neoplastic recurrence.

Discussion: The majority of animals with tracheal lymphoma are more than 7 years old; thus, this report is one of the few that describes this tumor type in a young cat, and therefore highlights the importance of considering tracheal lymphoma as a differential diagnosis in young cats with clinical findings compatible with this condition. The successful treatment carried out here was attributed to the immunophenotyping of the neoplasia, because when B cell trachea lymphoma is diagnosed early and correctly there is usually a good prognosis. Type $\mathrm{T}$ lymphomas exhibit a poorer clinical response through therapy than B cell lymphomas. As far as the authors know, this is only the fifth report in which immunophenotyping of a tracheal lymphoma in a cat has been performed. The relevance of studies involving the immunohistochemistry of this tumor type in cats is asserted, so that the differentiation between B or T cell lymphomas can provide greater accuracy in dealing with animals affected with this disease.
\end{abstract}

Keywords: felines, lymphoid neoplasia, immunohistochemistry.

${ }^{1}$ Veterinary Medicine Postgraduate Program; ${ }^{4}$ Department of Epidemiology and Public Health (DESP) \& ${ }^{5}$ Department of Veterinary Medicine and Surgery (DMCV), Rural Federal University of Rio de Janeiro (UFFRJ), Seropédica, RJ, Brazil. ${ }^{2}$ School of Veterinary Medicine \& ${ }^{3}$ Veterinary Medicine Postgraduate Program, Federal Fluminense University (UFF), Niterói, RJ. CORRESPONDENCE: M.P.B. Jardim [jardim.marii@ gmail.com]. Programa de Pós-Graduação em Medicina Veterinária - UFRRJ. Rodovia BR 465. Km 07 s/n. CEP 23890-000 Seropédica, RJ, Brazil. 


\section{INTRODUCTION}

Primary tracheal neoplasms are usually rare in small animals $[2,3]$. However, among the primary tracheal tumors found in felines are lymphoma, adenocarcinoma, carcinoma, squamous carcinoma and seromucinous carcinoma $[1-3,5,8,9,11,13]$.

Lymphoma is a proliferative disease of lymphoid origin that can affect any organ or tissue. Therefore, it can be classified according to its location as alimentary, mediastinal, multicentric and extranodal (when it affects organs that do not have lymphoid origin, such as the kidneys, skin, eyes, respiratory tract and central nervous system) [4].

Extranodal tracheal lymphomas are rare in the literature [2], especially with the use of immunophenotyping. Consequently, there is a lack of knowledge of their characteristics, and therefore, there is a need for further research into this tumor type in order to improve the clinical approach to cats with this disease.

The objective of this work is to report a case of extranodal B cell lymphoma in the trachea of a domestic cat, and to highlight the clinical and pathological characteristics of this neoplastic type.

\section{CASE}

A 5-year-old male domestic cat (Felis catus), of an oriental breed (Figure 1), with the main complaint of respiratory distress and loss of appetite, was taken to a veterinary clinic exclusively for cats in the city of Rio de Janeiro. The animal had a history of respiratory distress after exercise.

On clinical examination, inspiratory dyspnea was noted, with slight upper respiratory sounds, the

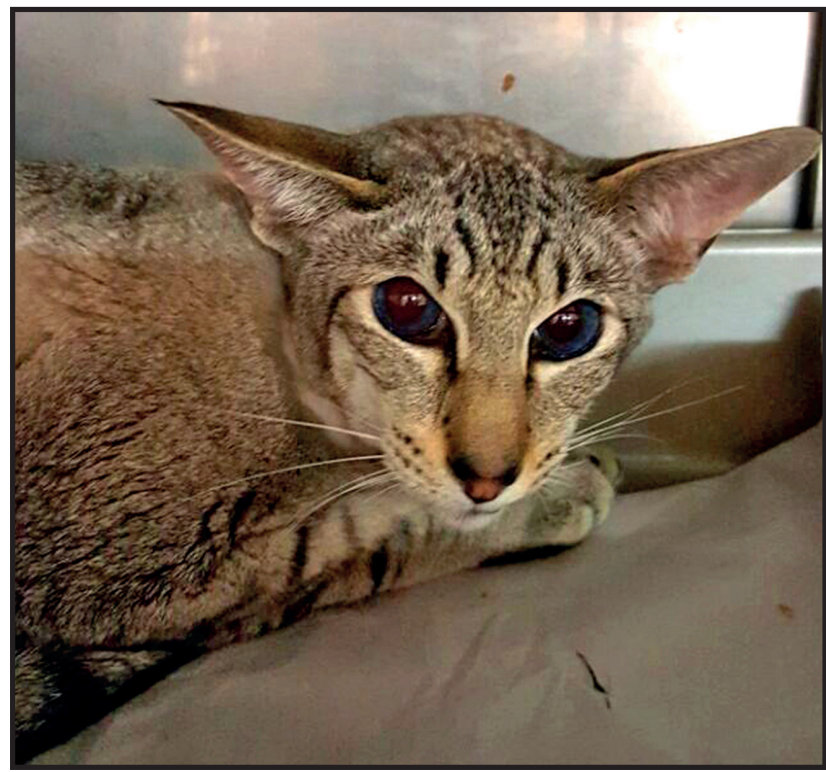

Figure 1. A domestic 5-year-old male cat (Felis catus) of an oriental breed with tracheal lymphoma.

body score was $3 / 9$, which classified the cat as sub-opti$\mathrm{mal} / \mathrm{lean}$ nutritionally, and the animal was hypothermic $\left(35.6^{\circ} \mathrm{C}\right)$. The ELISA serological test for feline viral leukemia antigen (FeLV) and feline immunodeficiency antibody (FIV) (SNAP FIV/FeLV Combo Test $\left.{ }^{\circledR}\right)^{1}$ were negative, and this was confirmed by the Polymerase Chain Reaction (PCR) method. Blood count and serum biochemical evaluations of the hepatic and renal functions showed no significant alterations.

The radiographic examination of the cervical-thoracic region revealed an image with an opacity in the cervical tracheal lumen, which occluded a part of the lumen (Figure 2), indicating a mass in the initial third of the trachea, with an estimated average diameter of $0.5 \mathrm{~cm}$.

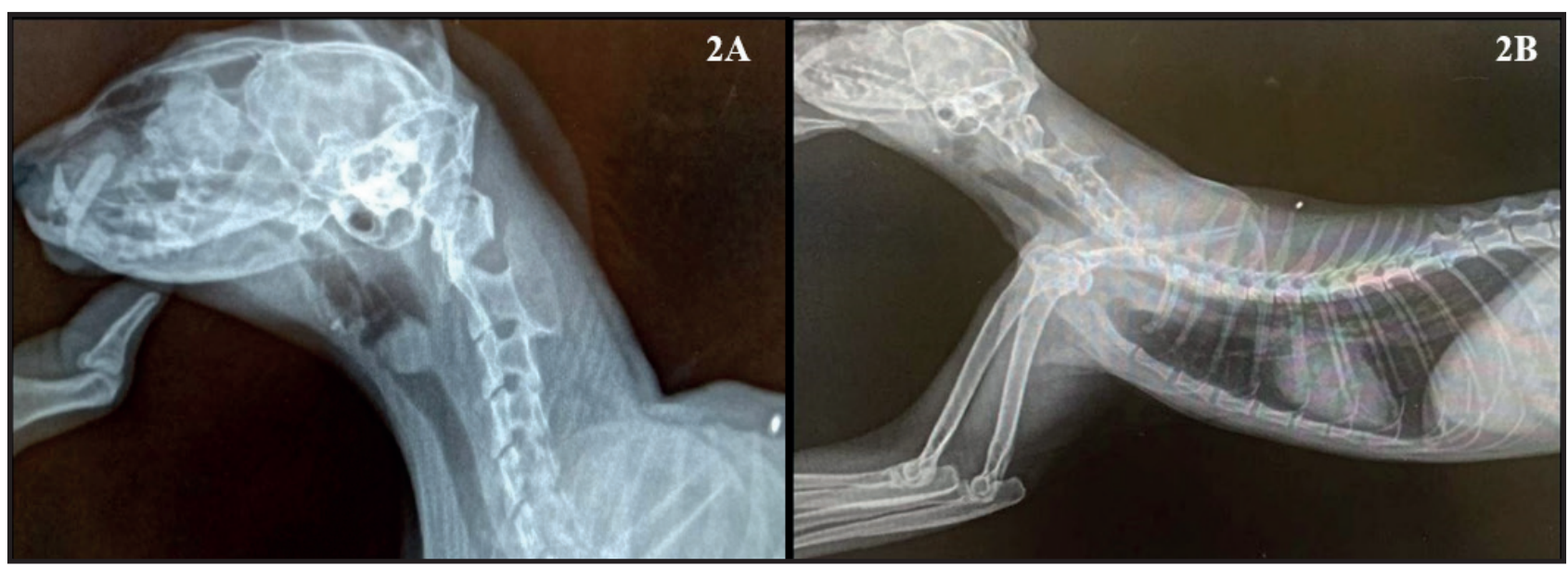

Figure 2. Radiographic examination of the thoracic cervical region from a latero-lateral view of the feline with tracheal lymphoma. A- Opacity of the cervical tracheal lumen, indicating a mass in the initial third of the trachea on the day the feline was admitted. B- Decreased tracheal mass after just 24 $\mathrm{h}$ after the chemotherapy. 
The patient was initially stabilized with a $0.2 \mathrm{mg} / \mathrm{kg}$ intravenous dose of midazolam hydrochloride (Dormire $\left.5 \mathrm{mg} / \mathrm{mL}^{\circledR}\right)^{2}$ and $24 \mathrm{~h}$ after admission was submitted to an oral cavity inspection. A fragment of the opaque mass of approximately $0.2 \mathrm{~cm}$ in diameter was excised from the tracheal region with $30 \mathrm{~cm}$ long Hartmann forceps. A cytopathological examination was made of the sample, which was then fixed in $10 \%$ formalin and sent to the Histopathology Laboratory of the Pathological Anatomy Sector of the Federal Rural University of Rio de Janeiro (UFRRJ). The material received was cleaved, processed, stained with Hematoxylin and Eosin (HE) [Eosina Amarelada $\left.{ }^{\circledR}\right) /$ Corante Hematoxilina de Harris $\left.{ }^{\circledR}\right]^{3}$, and then microscopically evaluated for histopathology and submitted to immunohistochemical analysis.

The cytopathological examination indicated material with high cellularity, composed of a homogeneous population of cells with rounded morphology compatible with large lymphocytes ( $>2$ erythrocytes), single and evident nucleoli, and was suggestive of lymphoma.

Based on the cytological diagnosis the therapeutic treatment applied was lomustine with a single oral dose of $10 \mathrm{mg}$ (Citostal ${ }^{\circledast} 10 \mathrm{mg} /$ capsule $^{4}$, vincristine sulfate with a single intravenous dose of $0.75 \mathrm{mg} / \mathrm{m}^{2}$ (Tecnocris $\left.{ }^{\circledR} 1 \mathrm{mg} / \mathrm{mL}\right)^{5}$, and methylprednisolone acetate with a single intramuscular dose of $20 \mathrm{mg}$ (Depo-medrol $\left.{ }^{\circledR} 40 \mathrm{mg} / \mathrm{mL}\right)^{6}$.

One day after this chemotherapy treatment, a second radiographic examination of the

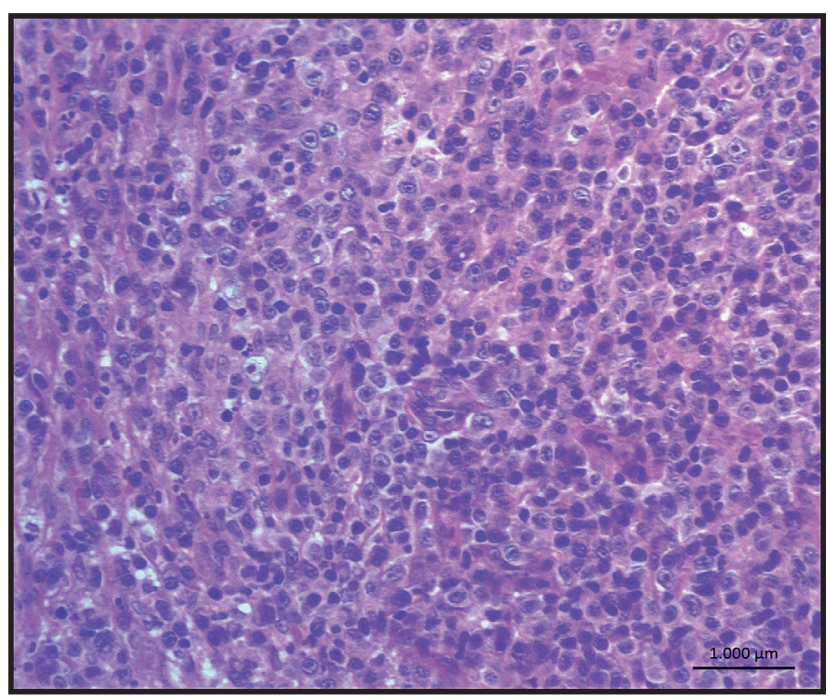

Figure 3. Histopathological examination showing neoplastic proliferation of a monomorphic round large sized cell population, with sparse to moderate cytoplasm and single and evident nucleoli [HE; 10x magnification]. cervical-thoracic region was taken. The radiographic image showed that the tracheal mass had shrunk and now had a $0.3 \mathrm{~cm}$ diameter. Seven days after the chemotherapy, the mass was no longer visible, demonstrating the full remission of the neoplasia.

Subsequently, the histopathological examination revealed neoplastic proliferation of a monomorphic population of large round cells that exhibited little cytoplasm, with single and evident nucleoli present. There was also moderate mitotic activity, where the number of mitoses varied from 0 to 3 per CGA (high rise field [magnification of 40x]), atypical for the time being (Figure 3). Thus, the microscopic changes were compatible with the diagnosis of large cell lymphoma.

In order to evaluate the immunohistochemical profile of the tumor, fragments were evaluated at the Immunohistochemistry Laboratory of the Federal Rural University of Rio de Janeiro. The positive results, which were obtained with a predominance of staining for the CD79 antibody and to a lesser extent for the CD3 antibody in the tumor cells, were compatible with B-cell lymphoma (Figure 4).

At a 36 month follow-up, the animal appeared in good health, with no respiratory clinical signs and no opaque mass in the trachea was seen in the radiographic examination.

\section{DISCUSSION}

The occurrence of lymphoma in the feline species has, for years, been associated with FIV and FeLV infections. Thymic and multicentric lymphomas

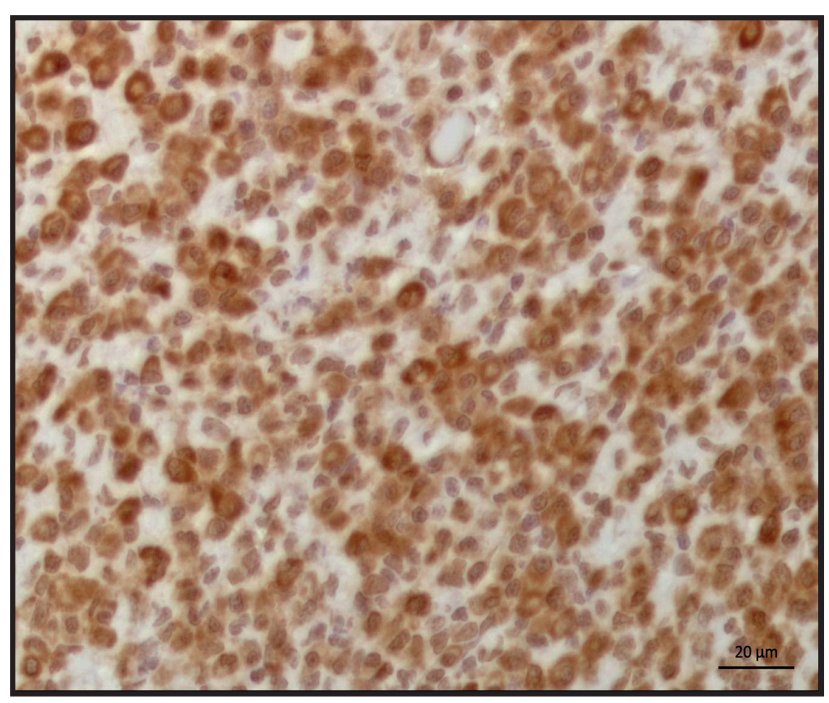

Figure 4. Immunohistochemical profile with positive labeling for the CD79 antibody in the cytoplasm of neoplastic cells [40x magnification]. 
generally originate from T lymphocytes, with a higher prevalence in cats under the age of seven and FeLV positive. On the other hand food lymphomas are predominantly derived from the lymphoid cells of the B type and generally affect elderly felines (over 7-years-old) and who are not positive for the feline viral leukemia virus $[4,11]$. This corroborated the present study as the neoplasm originating from B cells affected a FeLV negative feline. Furthermore, tracheal extranodal lymphoma does not seem to have a positive correlation with the aforementioned viruses $[1,2,5,8,10,11]$.

When considering the age of animals with tracheal lymphoma, this report is one of the few that describes this neoplastic occurrence in a young cat $[2,3]$, as normally this neoplasm is only observed in cats over 7-years-old [ $1-3,5,7,8,10,11]$. Thus the possibility of the occurrence of tracheal lymphoma in young animals should not be under estimated, especially when they have clinical signs and imaging findings that are compatible with this pathology.

Gender, on the other hand, does not seem to have a significant influence on the development of this pathology $[2,3,7]$, possibly because the condition has no correlation with the FeLV or FIV viruses that are more prevalent in male cats. [4].

In terms of race, the highest occurrence of tracheal lymphoma is observed in Siamese cats, although the disease can also occur in felines of other breeds or mixed breeds $[1-3,7,8,11]$, such as in this study.

The most common clinical signs of the condition are associated with the anatomical location of the mass and the consequent obstruction of the tracheal lumen and include dyspnea, respiratory sounds, choking, coughing, stridor, mouth breathing and cyanosis $[2,3,7,8]$. Intolerance to exercise is also a sign, thus justifying the visit to the veterinary clinic of the animal in this case [11].

A radiographic examination is considered fundamental to identify and locate a tracheal mass, as well as being the most commonly available technique and consequently the first-choice to make such a diagnosis $[2,3,7]$, along with the possibility of visualizing the opacification of the soft tissue and tracheal stenosis [8]. Such an examination was essential in the initial investigation of this work, although examinations such as bronchoscopy/tracheoscopy, computed tomography and even the surgical procedure of cervical exploration may allow a more thorough and detailed assessment of tracheal masses [1,2,5,7].

The recommended treatment for tracheal lymphoma includes chemotherapy, radiotherapy or a combination of both $[2,8]$. However, in the present study, instead of following a chemotherapy protocol, the chosen therapy was chemotherapies in a single dose, which resulted in the full recovery of the respiratory condition and no recurrence of the condition. Possibly such success was due to the neoplasm in question, because neoplasms originating from B-lymphocytes generally respond well to the established therapies [1]. However, they do not respond well in cases when the involvement of the tracheal is extremely severe, when surgical complications associated with the resection of the tracheal mass occur or when the condition is unclear and other diseases are present concomitant and euthanasia is required [9-11].

In 2012, Jelinek \& Hozmanova [9] diagnosed a case of tracheal B-cell lymphoma in cats due to the predominance of the positive labeling of the CD79 antibody to neoplastic cells, a fact that corroborates the current study, where primacy was obtained for the positive labeling in neoplastic cells of a B lymphocyte origin. As far as the authors know, immunophenotyping of this neoplasm has only been carried out in four studies to date, which indicates the lack of knowledge concerning the characteristics of this neoplastic type [1,9-11].

The definition of the $\mathrm{T}$ or $\mathrm{B}$ lymphoma with the aid of immunophenotyping provides extremely important prognostic data [12]. T-cell lymphomas, both in humans [6] and in Veterinary Medicine, have an unfavorable prognosis compared to B-lymphocyte neoplasms, due to the high rate of recurrence, little response to chemotherapy and result in early death $[12,14]$.

Mucosa-associated lymphatic tissue lymphomas (MALT), which are linked to the mucosal surface of the respiratory or intestinal system, are predominantly composed of small lymphocytes [15]. In the current study, large cell lymphomas were noted, making the morphological classification inherent to MALT lymphoma different from the tumor type observed in the present case.

The clinical examination, radiographic findings, histopathological and immunohistochemical evaluations enabled a diagnosis of tracheal B cell lymphoma in a domestic cat. This contributes to the information concerning the characteristics of this 
neoplastic type, which is scarce. Moreover, it affirms the importance of this report and other studies that evaluate the cell types that involve these neoplasms using immunophenotyping and thus enabling so that a more accurate prognosis is made and consequently a more appropriate therapy for each patient.

\section{MANUFACTURERS}

${ }^{1}$ Idexx Laboratories. Westbrook, ME, USA.

${ }^{2}$ Cristália Produtos Químicos Farmacêuticos Ltda. Itapira, SP, Brazil.
${ }^{3}$ Allkimia Comércio de Materiais para Laboratórios Ltda. Campinas, SP, Brazil.

${ }^{4}$ Bristol-Myers Squibb Farmacêutica S.A. São Paulo, SP, Brazil.

${ }^{5}$ Zodiac Produtos Farmacêuticos S/A. Pindamonhangaba, SP, Brazil. ${ }^{6}$ Wyeth Indústria Farmacêutica Ltda. Itapevi, SP, Brazil.

Funding. This study was financed in part by the Coordination for the Improvement of Higher Education Personnel - Brazil (CAPES) - Finance Code 001.

Declaration of interest. The authors declare no conflicts of interest. The authors alone are responsible for the content and writing of the paper.

\section{REFERENCES}

1 Bataller L., Tamborini A., L'Eplattenier H., Necova S. \& Robertson E. 2017. Successful treatment of tracheal lymphoma in a Siamese cat. Journal of Feline Medicine and Surgery Open Reports. 3(2): 1-6.

2 Brown M.R., Rogers K.S., Mansell K.J. \& Barton C. 2003. Primary intratracheal lymphosarcoma in four cats. Journal of the American Animal Hospital Association. 39(5): 468-472.

3 Carlisle C.H., Biery D.N. \& Thrall D.E. 1991. Tracheal and laryngeal tumors in the dog and cat: literature review and 13 additional patients. Veterinary Radiology. 32(5): 229-235.

4 Costa F.V.A., Souza H.J.M. \& Damico C.B. 2017. Linfomas e desordens mieloproliferativas em felinos. In: Costa F.V.A., Souza H.J.M., Cunha S.C.S. \& Corgozinho K.B. (Eds). Oncologia Felina. Rio de Janeiro: L.F. Livros, pp.315-356.

5 Dugas B., Hoover J. \& Pechman R. 2001. Computed tomography of a cat with primary intratracheal lymphosarcoma before and after systemic chemotherapy. Journal of the American Animal Hospital Association. 47(6): 131-137.

6 Gisselbrecht C., Gaulard P., Lepage E., Coiffier B., Brière J., Haioun C., Cazals-Hatem D., Bosly A., Xerri L., Tilly H., Berger F., Bouhabdallah R. \& Diebold J. 1998. Prognostic significance of T-cell phenotype in aggressive non-Hodgkin's lymphomas. Groupe d'Etudes des Lymphomes de l'Adulte (GELA). Blood. 92(1): 76-82.

7 Howard J., Fisher J. \& Tolbert M.K. 2017. Invasive tracheal neoplasia in eight cats: descriptive cases and review of the current literature. Journal of Feline Medicine and Surgery Open Reports. 3(1): 1-6.

8 Jakubiak M.J., Siedlecki C.T., Zenger E., Matteucii M.L., Bruskiewicz K.A., Rohn D. A. \& Bergman P. J. 2005. Laryngeal, laryngotracheal, and tracheal masses in cats: 27 cases (1998-2003). Journal of the American Animal Hospital Association. 41(5): 310-316.

9 Jelinek F. \& Hozmanova F. 2012. Lymphoma of the trachea in cat: a case report. Veterinarni Medicina. 57(3): 150-153.

10 Katayama M., Okamura Y., Katayama R., Sasaki J., Shimamura S., Uzuka Y., Kamishina H. \& Nezu Y. 2013. Presumptive acute lung injury following multiple surgeries in a cat. The Canadian Veterinary Journal. 54(4): 381-386.

11 Kim D.Y, Kim J.R., Taylor H.W. \& Lee Y.S. 1996. Primary extranodal lymphosarcoma of the trachea in a cat. The Journal of Veterinary Medical Science. 58(7): 703-706.

12 Ponce F., Magnol J.P., Ledieu D., Marchal T., Ledieu D., Turinelli V., Chalvet-Monfray K. \& Fournel-Fleury C. 2004. Prognostic significance of morphological subtypes in canine malignant lymphomas during chemotherapy. Veterinary Journal. 167(2): 158-166.

13 Rossi G., Magi G.E., Tarantino C., Taccini E., Mari S., Pengo G. \& Renzoni G. 2007. Tracheobronchial neuroendocrine carcinoma in a cat. Journal of Comparative Pathology. 137(2-3): 165-168.

14 Ruslander D.A., Gebhard D.H., Tompkins M.B., Grindem C.B. \& Page R.L. 1997. Immunophenotypic characterization of canine lymphoproliferative disorders. In Vivo. 11(2): 169-172.

15 Valli V.E, Jacobs R.M, Parodi A.L, Vernau V. \& Moore P.F. 2002. Histological classification of hematopoietic tumors of domestic animals. The Armed Forces Institute of Pathology. American Registry of Pathology, World Health Organization. 8(2): 42-43. 